\title{
Business Impact of COVID-19 Pandemic on Pharmacy Shops of Dharan-18: A Sample Survey
}

\author{
Sumitra Devi Regmi \\ Lecturer \\ Faculty of Management, Mahendra Multiple Campus, Dharan, Tribhuvan University, Nepal \\ Email: regmisumitrabkb@gmail.com \\ DOI: https://doi.org/10.3126/dristikon.v10i1.34559
}

\begin{abstract}
The present study aims to describe the effect of the COVID-19 pandemic and the governmentimposed lockdown on the business activities of pharmacy shop owners (as small business operators) in the locality of Dharan-18. A sample survey was carried out in 32 participants using a self-designed and self-administered questionnaire comprising participants' demographic details and 14 question items concerning the impact of the pandemic and lockdown on their businesses. All the participants responded. The results show that all the pharmacy operators were adversely affected by the pandemic and the imposed lockdown. Most of the businesses temporarily suspended their operations while some stopped operating. The essential supplies and access to goods and services as well as financial access have been severely hindered; however, no remarkable price hike has been observed. The expectations of the participants about changes in near future lack consistencies. The participants have expressed lack of confidence in carrying out business in the forthcoming days. In conclusion, the COVID-19 pandemic and the government-imposed lockdown has affected almost all of the pharmacy operators in the locality of Dharan-18.
\end{abstract}

Keywords: business impact, COVID-19 pandemic, economic impact, lockdown, small business

\section{Introduction}

Coronavirus disease 2019 has not only adversely affected our public health but also has caused major damages in our economy at its core all around the globe. As such, coronaviruses have been identified for more than 50 years as important human and animal pathogens. A novel coronavirus was identified at the end of 2019 that caused cases of pneumonia in the city of Wuhan in Hubei Province of China that captured the attention of the whole world. It rapidly spread within and outside the city causing an epidemic in China and subsequently other countries of the world causing a pandemic. The coronavirus disease 2019 was named COVID19 by the World Health Organization (WHO) in February 2020 (WHO, 2020) and the virus was named severe acute respiratory syndrome coronavirus-2 (SARS-CoV-2).

Cases of COVID-19 have been reported from all the continents (except Antarctica) following the first report of cases in Wuhan, China. Globally, millions of cases have been 
reported and increasingly being reported. Actually, the reported case counts underestimate the overall burden of the disease as only fraction of infections are diagnosed and counted.

United Nations Development Program (UNDP) has warned that the COVID-19 pandemic is far more than a health crisis and is affecting societies as a whole. The effect may vary country to country but is most likely to increase poverty and inequality (UNDP, 2020). Assessment of the impacts of the COVID-19 crisis on economies and societies is essential to draw attention of the governments for their appropriate responses. If we do not respond to the problem now, our lives and livelihoods will be compromised for years to come.

The pandemic has caused widespread and far reaching consequences much beyond the spread of the virus and efforts to contain it. It has caused the largest global recession in history with large fraction of the population at the time being under lockdown (World Bank, 2020a). Supply shortages have occurred due to panic buying and disruption to factories and logistics leading to price hikes (Malden \& Stephens, 2020 April 21). Shortages of pharmaceuticals have been reported (United States Food and Drug Administration, 2020). About 21 million of job losses have been estimated in South Asia alone in the first quarter of 2020 (Pandey, 2020).

The pandemic has undoubtedly caused impacts on businesses of every size; however, small and medium sized businesses have been more severely affected because of their higher level of vulnerability and lower resilience related to their size (OECD, 2020). Increasing number of articles on economic impacts is being published from all around the globe including our country; but reports on ground level assessment of the impact of COVID-19 on small businesses in our setting are lacking.

\section{Research Problem}

Businesses of all sizes including the medium and small sizes throughout the world have been impacted by the pandemic as well as public restrictions imposed by governments. Small and medium sized businesses constitute the major share of the business sector and contribute to the economy; unfortunately, owing to their size, they are more vulnerable to bankruptcy as they lack financial resilience. Numerous reports on various impacts of the pandemic and lockdown can be found on literature search-including reports from our own country. However, setting specific reports are lacking; we do not know the extent to which small businesses like groceries, pharmacy shops etc. in our locality have been affected.

\section{Research Objective}

The present study aims to find out as to how the pharmacy shops (as representing small businesses) in Dharan-18 locality have been impacted by the COVID-19 pandemic and the lockdown imposed by the government. 


\section{Literature Review}

The name of coronavirus comes from the word corona (Italian and Spanish term for crown) as the structure of the virus is crown-like when viewed through an electron microscope. Coronaviruses have been described for more than 50 years (Weiss \& Martin, 2005). On February 11, 2020, a new virus was named - the novel coronavirus (2019-nCoV-2) (Coronaviridae Study Group of the International Committee on Taxonomy of Viruses, 2020).

COVID-19 outbreak is not the first case of coronavirus disease as several coronaviruses have caused serious problems in humans and animals in the past e.g., Severe Acute Respiratory Syndrome coronavirus (SARS-CoV), Middle East Respiratory Syndrome coronavirus (MERS-CoV) and Porcine Epidemic Diarrhea virus (PEDV). Because of high mutability of these viruses, they cross species barriers and adapt to new host. These viruses therefore often show emergence and re-emergence time to time (Lau \& Chan, 2015).

Guo et al. (2020) described the clinical characteristics of COVID-19 that, as an emerging acute respiratory infectious disease, COVID-19 primarily spreads through the respiratory tract by droplets, respiratory secretions, and direct contact for a low infective dose. COVID-19 is contagious during the latency period. It is highly transmissible in humans, especially in the elderly and people with underlying diseases. Most adults and children with SARS-CoV-2, COVID-19 infection present with mild flu like symptoms and a few patients are in critical conditions and can rapidly develop acute respiratory syndrome, respiratory failure, multiple organ failure and even death.

In the best-case scenario in 2020, which is defined as two month duration of travel bans and a sharp decline in domestic demand, the monetary loss of global Gross Domestic Product (GDP) is expected to be about 76.7 billion USD due to COVID-19 outbreak. In a worst-case scenario, defined as six month duration of travel bans, the global GDP is predicted to lose about 346.98 billion USD (Duffin, 2020). In REANDA (2020) report, it has been noted:

While there is no way to tell exactly what the economic damage from the global COVID-19 novel coronavirus pandemic will be, there is widespread agreement among economists that it will have severe negative impacts on the global economy. Early estimates predicated that, should the virus become a global pandemic, most major economies will lose at least 2.4 percent of the value of their gross domestic product (GDP) over 2020, leading economists to already reduce their 2020 forecasts of global economic growth down from around 3.0 percent to 2.4 percent. To put this number in perspective, global GDP was estimated at around 86.6 trillion USD in 2019 - meaning that just a 0.4 percent drop in economic growth amounts to almost 3.5 trillion USD in lost economic output. However, these predictions were made prior to COVID-19 becoming a global pandemic, and before the implementation of widespread restrictions 
on social contact to stop the spread of the virus. Since then, global stock markets have suffered dramatic falls due to the outbreak, and the Dow Jones reported its largest-ever single day fall of almost 3,000 points on 16 March 2020 - beating its previous record of 2,300 points that was set only four days earlier.

The economic damage caused by the COVID-19 pandemic is largely driven by a fall in demand, meaning that there are no consumers to purchase the goods and services available in the global economy. This dynamic can be clearly seen in heavily affected industries such as travel and tourism. To slow the spread of the virus, countries have placed restrictions on travel; many people cannot purchase flights for holidays or business trips. This reduction in consumer demand causes airlines to lose planned revenue and they then need to cut their expenses by reducing the number of flights they operate. Without government assistance, eventually airlines will also need to lay off staff to further cut their costs. The same dynamic applies to other industries, for example with falling demand for oil and new cars as daily commutes, social events and holidays are no longer possible. As companies start cutting staff to make up for lost revenue, the worry is that this will create a downward economic spiral when these newly unemployed workers can no longer afford to purchase unaffected goods and services. To use retail as an example, an increase in unemployment will compound the reduction in sales that occurred from the closure of shop fronts, cascading the crisis over to the online retail segment (which has increased throughout the crisis). It is this dynamic that has economists contemplating whether the COVID-19 pandemic could lead to a global recession on the scale of the Great Depression (REANDA, 2020 p. 4).

Increasing positive tests and reported deaths in Nepal and other countries due to novel coronavirus (COVID-19) has created widespread panic and concerns in the people. Nepal is experiencing abrupt and widespread cessation of economic activity due to outbreak of this virus. The impact has already started to surface in number of sectors like tourism, trade and production linkages, supply and health. According to a regional brief report of the World Bank, the pandemic is estimated to cause a US\$460 million potential loss to GDP, cancellation of the Visit Nepal Campaign, 230,000 jobs at risk, dismissal of 20,000 tour and trekking guides, and closure of 2,600 trekking agencies (World Bank, 2020b).

In India, economists expect the near-term impact of the outbreak to be limited to the supply chains of major conglomerates, especially pharmaceuticals, fertilizers, automobiles, textiles and electronics. A severe impact on global trade logistics is also expected due to disruption of logistics in mainland China, but due to the combined risk with regional geopolitical tensions, wider trade wars and Brexit (The Economic Times, 2020 February 13).

In fact, the whole range of businesses - from large to small — have been adversely affected. However, the effect on small and medium-sized enterprises (SMEs) is especially 
severe, particularly because of higher levels of vulnerability and lower resilience related to their size. The Organization for Economic Cooperation and Development (OECD) reports:

Worldwide, SMEs account for the vast majority of companies, value added and employment. SMEs often have a more limited number of suppliers. In some cases, this may shelter them from the shock. At the beginning of the pandemic outbreak in China, this appeared to be the case with German SMEs operating more in regional supply chains and therefore less affected by developments in Asia. In other cases, SMEs may rely on suppliers from countries and regions with more COVID-19 cases, increasing their vulnerability. Similarly, obstacles in transportation by sea, road or air affect these SMEs. Some SMEs are particularly vulnerable to the disruption of business networks and supply chains, with connections with larger operators and the outsourcing of many business services critical to their performance. Over the longer term, it may be difficult for many SMEs to re-build connections with former networks, once supply chains are disrupted and former partners have set up new alliances and business contracts (OECD, 2020 p. 3).

Businesses, including SMEs, have to bear the consequences of a reduction in global demand for their products and services. OECD further reports:

This impact may particularly be felt in specific sectors such as tourism, but also amongst those SMEs catering for local markets where containment measures have been introduced. SMEs may have less resilience and flexibility in dealing with the costs these shocks entail. Costs for prevention as well as requested changes in work processes, such as the shift to teleworking, may be relatively higher for SMEs given their smaller size, but also, in many instances, the low level of digitalization and difficulties in accessing and adopting technologies. If production is reduced in response to the developments, the costs of underutilized labor and capital weigh greater on SMEs than larger firms. Furthermore, SMEs may find it harder to obtain information not only on measures to halt the spread of the virus, but also on possible business strategies to lighten the shock and government initiatives available to provide support (OECD, 2020 p. 4).

Koirala and Acharya (2020) have concluded in their article that there is direct impact of novel coronavirus outbreaks on Nepalese economy as Nepal is fully dependent on other countries for imports. The economic and social isolation cost is likely to be higher. The remittance flow forms important economic source for Nepal; therefore, the impact is likely to be extended and may go beyond 5 years. Labor market and education system have also been badly affected. They further conclude: 
Unemployment will be higher in tourism related industry in days to come. This is true that just calculating the impact on tourist trips, hotels, declines in retail trade, decline in remittance, close down of education centre are not enough to get the real picture of impact on economy in Nepal. There are some linkages in economy across various sectors both direct and indirect impact need to be calculated as economic shock of one nation will be directly linked to other nation in this global world. The impact illustrated through the qualitative data is far greater than the cost to a health budget of treatment of the cases involved. The more persistent shock is Corona lasting for longer than anyone hopes in this increased globalization. There is need of global monitoring and coordination mechanisms in containing both economic and microbial epidemics as the impact are higher than expected (Koirala \& Acharya, 2020).

Poudel and Subedi (2020) highlight that Nepal, being the fifth most remittancedependent country, sends millions of labor migrants abroad every year for international labors. While remittances range up to $25 \%$ of the gross domestic product (GDP), migrant remittances may decline during the time of COVID-19, limiting the source of income of households in Nepal. The declination in remittance can limit the families from getting out of poverty, paying off unscrupulous loans, and investment in education, health and land.

\section{Materials and Methods}

The design of the study was descriptive sample survey. The participants were the pharmacy shop owners in Dharan-18 area of Sunsari District. The instrument used was a 14item self-designed questionnaire prepared first in English followed by translation into Nepali validated by reverse translation. The questions focused mainly on the financial performance and operational performance of the business and their expected change in near future.

Convenient sampling technique was used. Data were collected using self-administered questionnaire with closed questions. The questionnaires were distributed on $30^{\text {th }}$ June 2020 and the responses were collected on the $1^{\text {st }}$ of July 2020.

\section{Procedural Detail}

The number of pharmacy shops operating in the intended area of research was found out from the local representative of the local occupational body of the pharmacy owners. As learned from the representative of the local body, there are about 135 functional pharmacy shops in the area; the number was used for estimating the required sample size.

Verbal consent was obtained from each participant prior to handing over the questionnaire. After the participants returned the questionnaires back the data were entered into Microsoft excel spreadsheet. For data analysis, the statistical software JASP (version 0.13.1, University of Amsterdam) was used. Data were analyzed using descriptive statistics and presented as text and tables as appropriate. 


\section{Sample Size Estimation}

Sample size was estimated based on previous data from elsewhere which has shown that almost every business has been adversely affected by the coronavirus pandemic (OECD, 2020). Therefore, assuming more than $90 \%$ of the businesses to be affected, accepting a precision of \pm 10 and using sample size formula for finite population, a sample size of 26 or more are required to estimate the proportion at $95 \%$ confidence level. A sample size of 32 was taken considering a possibility of $20 \%$ nonresponses.

\section{Results and Discussion}

\section{Participants' Characteristics}

All the 32 participants responded and returned the questionnaires. The participants' demographic details are given in table 1 .

\section{Table 1}

Participants' Characteristics

\begin{tabular}{|l|l|}
\hline Variables & Value \\
\hline Gender ratio (Male: Female) & $30: 2$ \\
\hline Mean age \pm SD in years & $39.45 \pm 8.84$ \\
\hline Median age (IQR) in years & $40.5(32.75-45.00)$ \\
\hline Mean years \pm SD of involvement in business & $12.64 \pm 9.34$ \\
\hline Median years (IQR) of involvement in business & $10(5-20)$ \\
\hline Mean number of individuals employed \pm SD & $2.06 \pm 1.5$ \\
\hline Median number of individuals employed (IQR) & $2(1-2)$ \\
\hline Level of education as number & \\
SLC & $9(28.13 \%)$ \\
HSS & $16(50.00 \%)$ \\
Bachelors & $6(18.75 \%)$ \\
Masters & $1(3.13 \%)$ \\
\hline
\end{tabular}

Note. SD - standard deviation; IQR - inter quartile range; SLC - school leaving certificate; HSS - higher secondary school.

\section{Financial and Operational Performance}

Twenty (62.5\%) of the respondents temporarily suspended their businesses while 6 $(18.75 \%)$ continued and $6(18.75 \%)$ remained closed throughout. All the respondents had their 
businesses turnover outside their normal range i.e. all of them were adversely affected by the pandemic and it was substantially lower than their normal performances. All of the respondents attributed the decreased performances to COVID-19 and the lockdown.

For $26(81.25 \%)$ respondents, the supply side was adversely affected while for four $(12.5 \%)$ it was not affected and the remaining felt that it was not applicable to them. Eighteen (56.25\%) of the respondents experienced no access to goods and services during the lockdown period while $14(43.75 \%)$ used alternative means for it. Of all, 20 (62.5\%) respondents experienced no price change during the lockdown; eight (25\%) experienced increased price in some goods and decreased in some other goods; two (6.25\%) experienced increased price change. All but one respondent experienced decreased financial access during the initial lockdown; the remaining one was uncertain about it.

\section{Expected changes}

Six $(18.75 \%)$ of the participants expected increased turnover to some extent in near future while the same number of participants expected it to decrease to some extent and four (12.5\%) expected it to decrease substantially. Fourteen (43.75\%) were not sure about it. The response on expected supply status in near future was inconsistent; 12 (37.5\%) expected supply to become harder while $14(43.75 \%)$ expected it to become easier to some extent.

Sixteen $(50 \%)$ of the respondents expected the price not to change in the near future while $12(37.5 \%)$ expected it to generally increase and four $(12.5 \%)$ were not sure about it. Among all, 19 (58.57\%) respondents felt not being confident to continue the business while 13 (40.63\%) were unable to decide.

\section{Findings}

The main finding of the sample survey is that no pharmacy operators (as small businesses) in the study area have remained unaffected by the COVID-19 pandemic (and the initial nationwide lockdown imposed by the government). Despite their businesses being essential nature in such a situation, almost two-thirds of the sample population temporarily suspended their businesses while only one-fifth were able to continue.

The essential supplies have been severely hindered by the pandemic as perceived by the participants of the study. Similarly, access to goods and services have been limited to such an extent that majority have had no options; only few lucky ones have been able to resort to alternative means to tide over the crisis. However, it is noteworthy that there have been no remarkable price hikes as experienced by the participants though almost all the participants faced hindrance in getting financial access.

The expectations in the business turnover in the near future have been at odds as most of the respondents are not sure on the issue. In the same line, the expectation on the access and 
supply system in the near future has also been at variance. Half of the respondents expect no remarkable change in the price of goods and services in the near future; most of the remaining respondents expect a price rise. The participants of the present study have expressed either they have lost their confidence to carry on with their businesses or have been hopelessly uncertain about the forthcoming days.

Although the present study has not primarily aimed at finding out the psychological aspects of the participants, the findings are suggestive of lack of confidence and psychological upset; this indicates a need of study in this aspect as well.

The study has been carried out only in the cohort of pharmacy operators, comparison cannot be made with other small businesses (e.g., groceries). Also, this study has focused only on small businesses and does not include larger entrepreneurs.

No report was found in the literature search of any study involving similar participants and settings that could have allowed direct comparison with the present study. However, studies from different settings have been reported. Bartik et al. (2020) have reported temporary closure in $43 \%$ of small businesses and fall of employment by $40 \%$ in American settings comparing the findings with the Great Depression of the 1930s. Buffington et al. (2020) from their survey in USA have reported that almost $90 \%$ of small businesses have experienced strong $(51 \%)$ or moderate $(38 \%)$ negative impact from the pandemic; $45 \%$ of businesses experienced disruptions in supply chains; $25 \%$ of businesses have less than 1-2 months cash reserves. OECD (2020) has reported two thirds of small businesses adversely impacted by the pandemic in Australia and $81 \%$ in Canada.

According to a recent report from India (The Economic Times, 2020, August 17), almost half (46\%) of Indian businesses covered under a survey felt 'very strongly' impacted by the pandemic, yet majority (54\%) felt they were 'as well prepared as they possibly could be' showing surprising resilience.

\section{Limitations}

The major limitation of the sample survey is that the tool used was of self-administered questionnaire which does not allow for any clarification by the participants. The second important limitation is that the study represents a small locality and only involving pharmacy operators which might confine the generalizability of the findings.

Despite its limitations the present study provides ground level information on the impacts made by the COVID-19 pandemic and the imposed lockdown.

\section{Conclusion}

COVID-19 pandemic has adversely affected pharmacy shop operators in the studied population to the extent that most of the participants suspended their business activities. The 
business turnover has decreased drastically and the supply has been hindered intractably. The participants reveal lack of confidence and hope about the prospect of their business in the near future.

\section{Acknowledgements}

The author thanks Mr. Subhash Paudel (owner, Gumba Pharmacy, Dharan-18) for providing information about the operating pharmacy shops list and helping in collecting the data. The author also feels indebted to the participants for their consent, cooperation and timely responses.

\section{References}

Bartik, A. W., Bertrand, M., Cullen, Z., Glaeser, E.L., Luca, M., \& Stanton, C. (2020). The impact of COVID-19 on small business outcomes and expectations. Proceedings of the National Academy of Sciences (PNAS) 117 (30), 17656-17666. https://doi.org/10.1073/pnas.2006991117

Buffington, C., Dennis, C., Dinlersoz, E., Foster, L., \& Klimek, S. (2020). Measuring the effect of COVID-19 on U.S. small businesses: The small business pulse survey. https://www2.census.gov/ces/wp/2020/CES-WP-20-16.pdf

Coronaviridae Study Group of the International Committee on Taxonomy of Viruses. (2020). The species severe acute respiratory syndrome-related coronavirus: Classifying 2019-nCoV and naming it SARS-CoV-2. Nature Microbiology, 5(4), 536-544. https://doi.org/10.1038/s41564-020-0695-z

Duffin, E. (2020, June 18). Forecasted monetary global GDP loss due to COVID-19, by scenario 2020. Statista. 2020 https://www.statista.com/statistics/1102971/covid-19-monetary-globalgdp-loss-scenario/

Guo, Y. R., Cao, Q. D., Hong, Z. S., Tan, Y. Y., Chen, S. D., Jin, H. J., Tan, K. S., Wang, D. Y., \& Yan, Y. (2020). The origin, transmission and clinical therapies on coronavirus disease 2019 (COVID-19) outbreak - an update on the status. Military Medical Research, 7(1), 11. https://doi.org/10.1186/s40779-020-00240-0

Koirala J., \& Acharya, S. (2020). Impact of Novel Corona virus (COVID-19 or 2019-nCoV) on Nepalese Economy. SSRN Electronic Journal. https://doi.org/10.2139/ssrn.3560638

Lau, S. K. P., \& Chan, J. F. W. (2015). Coronaviruses: emerging and re-emerging pathogens in humans and animals. Virol J, 12, 209. https://doi.org/10.1186/s12985-015-0432-z

Malden K., \& Stephens, S. (2020, April 21). Cascading economic impacts of the COVID-19 outbreak in China. U.S.-China Economic and Security Review Commission Staff Research Report. https://www.uscc.gov/sites/default/files/2020-

4/Cascading_Economic_Impacts_of_the_Novel_Coronavirus_April_21_2020.pdf 
OECD (Organization of Economic Cooperation and Development). (2020). Coronavirus (COVID19): SME policy responses. http://www.oecd.org/coronavirus/policyresponses/coronavirus-covid-19-sme-policy-responses-04440101/

Pandey, K. (2020, July 2). COVID-19: $400 \mathrm{mln}$ jobs lost in Q2 2020. DownToEarth. https://www.downtoearth.org.in/news/economy/covid-19-400-mln-jobs-lost-in-q2-2020says-international-labour-organization-72086

Poudel, K., \& Subedi P. (2020). Impact of COVID-19 pandemic on socioeconomic and mental health aspects in Nepal. International Journal of Social Psychiatry, 1-8. https://doi.org/10.1177/0020764020942247)

REANDA. (2020, April 16). Potential impact of COVID-19 on Nepalese economy. http://www.reanda-international.com/News_Photo/pdf/P_i_C_N_E.pdf)

The Economic Times. (2020, February 13). How coronavirus pandemic can impact India, world economy - Near-term impact on India Inc. The Economic Times. https://economictimes.indiatimes.com/markets/stocks/news/-how-coronavirus-outbreakcan-impact-india-world-economy/near-term-impact-on-india-inc/slideshow/74114828.cms

The Economic Times. (2020, August 17). Indian businesses resilient despite novel coronavirus impact: HSBC's Navigator report. The Economic Times. https://economictimes.indiatimes.com/markets/coronavirus-impact-on-

United Nations Development Program. (2020). COVID-19 and human development: Assessing the crisis, envisioning the recovery. 2020 Human Development Perspectives. http://hdr.undp.org/sites/default/files/covid-19_and_human_development_0.pdf

United States Food and Drug Administration. (2020). Drug shortages response |COVID-19. https://www.fda.gov/drugs/coronavirus-covid-19-drugs/drug-shortages-response-covid-19

Weiss, S. R., \& Navas-Martin, S. (2005). Coronavirus pathogenesis and the emerging pathogen severe acute respiratory syndrome coronavirus. Microbiology and molecular biology reviews: MMBR, 69(4), 635-664. https://doi.org/10.1128/MMBR.69.4.635-664.2005)

World Health Organization. (2020). Coronavirus disease 2019 (Covid-19). Situation Report. https://www.who.int/emergencies/diseases/novel-coronavirus-019/situation-reports

World Bank. (2020a, June 8). COVID-19 to plunge global economy into worst recession since World War II. Press Release. https://www.worldbank.org/en/news/pressrelease/2020/06/08/covid-19-to-plunge-global-economy-into-worst-recession-since-worldwar-ii

World Bank. (2020b). COVID-19 and tourism in South Asia: Opportunities for sustainable regional outcomes. https://openknowledge.worldbank.org/bitstream/handle/10986/34050/COVID19-and-Tourism-in-South-Asia-Opportunities-for-Sustainable-RegionalOutcomes.pdf?sequence $=6$ 